\title{
Infected Dentigerous Cyst with Keratinization - A Rare Phenomenon
}

\author{
Swathi Shammi ${ }^{1}$, Ramvihari Thota르, Abdul Wahab P.U. ${ }^{3}$, Pradeep Dhasarathan ${ }^{4}$, Senthil Murugan P. ${ }^{5}$ \\ 1, 2, 3, 4, 5 Department of Oral and Maxillofacial Surgery, Saveetha Dental College and Hospitals, Saveetha \\ Institute of Medical and Technical Sciences, Saveetha University, Chennai, Tamil Nadu, India.
}

\section{INTRODUCTION}

Dentigerous cysts are the second most common odontogenic cysts next to radicular cysts and also the most common developmental cyst of the jaws. ${ }^{1}$ The term dentigerous literally means "tooth bearing."2 The term was coined by Paget in 1853 and arises from the crowns of impacted, embedded or unerupted teeth. ${ }^{3}$ Dentigerous cysts which are associated with supernumerary teeth accounts for $5 \%-6 \%$ and about $90 \%$ of them are dentigerous cysts associated with maxillary mesiodens. ${ }^{4}$

Dentigerous cyst appears as a result of accumulation of fluid between the crown of an unerupted tooth and the surrounding reduced enamel epithelium. They are twice as common in males as compared to females; with about $30 \%$ of them occurring in the maxilla. ${ }^{5}$ Supernumerary teeth being most common in the maxilla have a strong predilection for the anterior region. Only $5 \%$ of dentigerous cysts are associated with supernumerary teeth. The most common clinical presentation of a dentigerous cyst with a supernumerary tooth is seen in the first four decades of life. ${ }^{6}$

The present paper reports a case of an infected dentigerous cyst associated with an ectopic positioned canine and impacted lower right premolars which had keratinized lining.

\section{PRESENTATION OF CASE}

A 10-year-old boy reported to the dental OPD (Out Patient Department) with a chief complaint of swelling in the lower right back tooth since 1.5 years (Figure 1). The swelling was not associated with pain. But patient complained of bad breath and bleeding from that site. Bleeding occurs 4 - 5 times a day and increases during night time. The bleeding gets spontaneously resolved. No history of trauma and no signs of paraesthesia.
Corresponding Author: Dr. Swathi Shammi. D-14, Arihant Amara Apartments, Poonamallee, Chennai - 600077 Tamil Nadu, India.

E-mail: swathisshammi@gmail.com

DOI: $10.14260 /$ jemds/2020/747

How to Cite This Article:

Shammi S, Thota R, Wahab PUA, et al. Infected dentigerous cyst with keratinization - a rare phenomenon. J Evolution Med Dent Sci 2020;9(45):34023407, DOI: $10.14260 /$ jemds/2020/747

Submission 05-07-2020,

Peer Review 01-09-2020

Acceptance 08-09-2020,

Published 09-11-2020.

Copyright (C) 2020 Swathi Shammi et al. This is an open access article distributed under Creative Commons Attribution License [Attribution 4.0 International (CC BY 4.0)] 

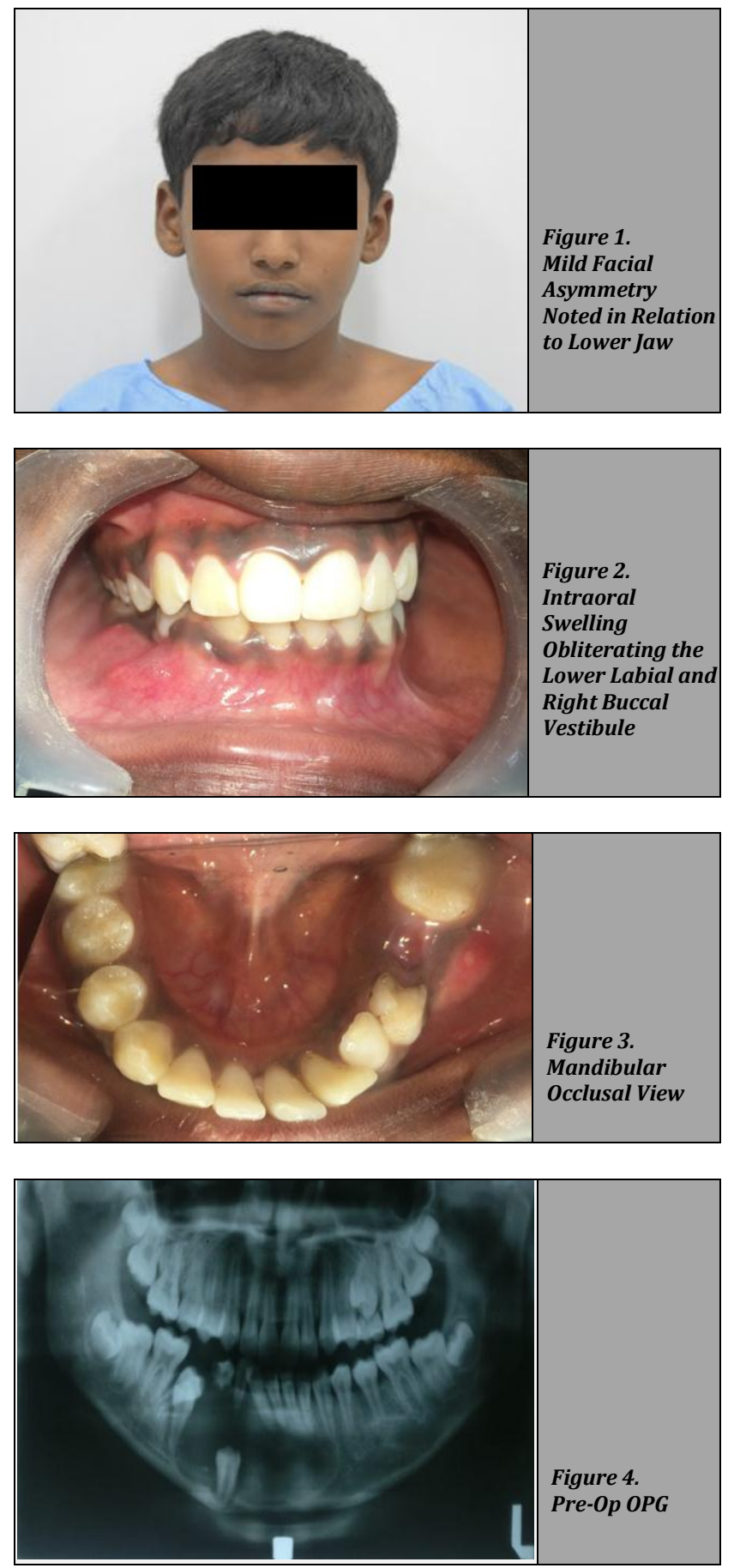

On clinical examination, an extraoral solitary diffuse swelling was seen involving the right side of lower jaw, $2 \mathrm{~cm}$ away from the angle of mouth extending till the right body of mandible. Extraoral swelling was nontender. No ulcerations or pulsations were felt. And there were no signs of bleeding, pus discharge or inflammation. Intraoral examination revealed a swelling about $4 \mathrm{~cm} \times 4 \mathrm{~cm}$ in the mandibular right buccal vestibule which extended from the deciduous lower right canine to the permanent lower right first molar (Figure 2). The swelling caused obliteration of lower right buccal vestibule (Figure 3). The swelling was tender on palpation, firm in consistency with the overlying mucosa appearing inflamed and erythematous. The mandibular right second molar was grade II mobile and also tender on vertical percussion.
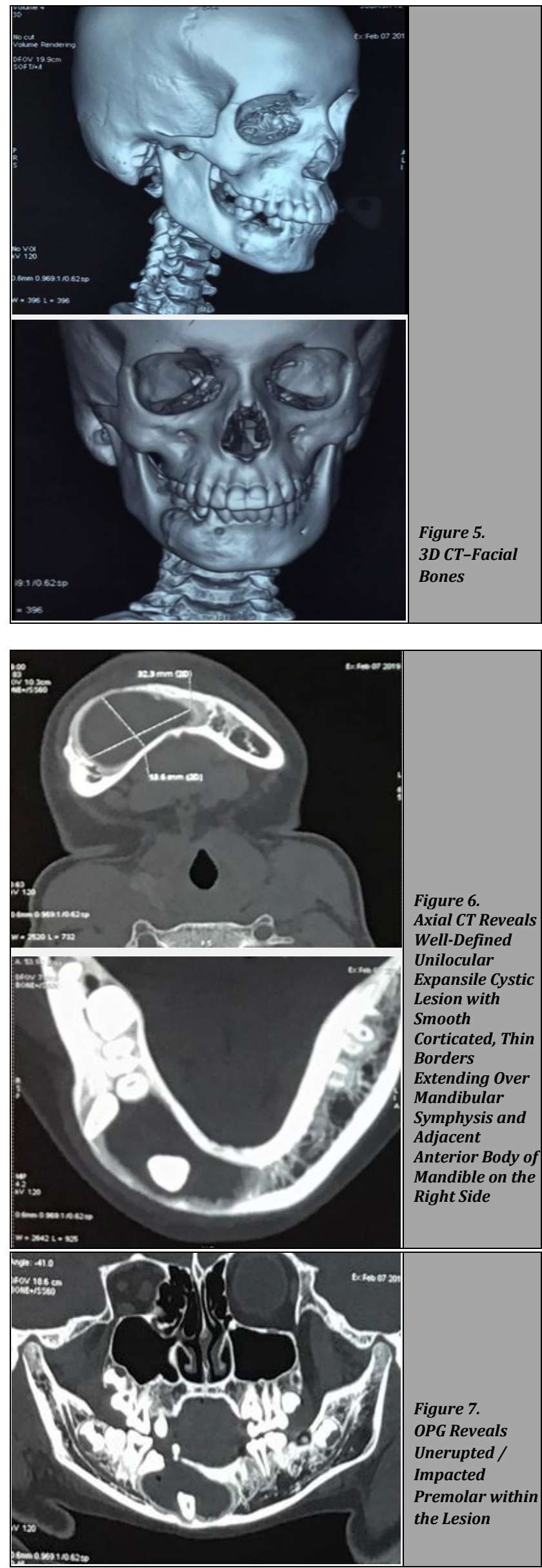


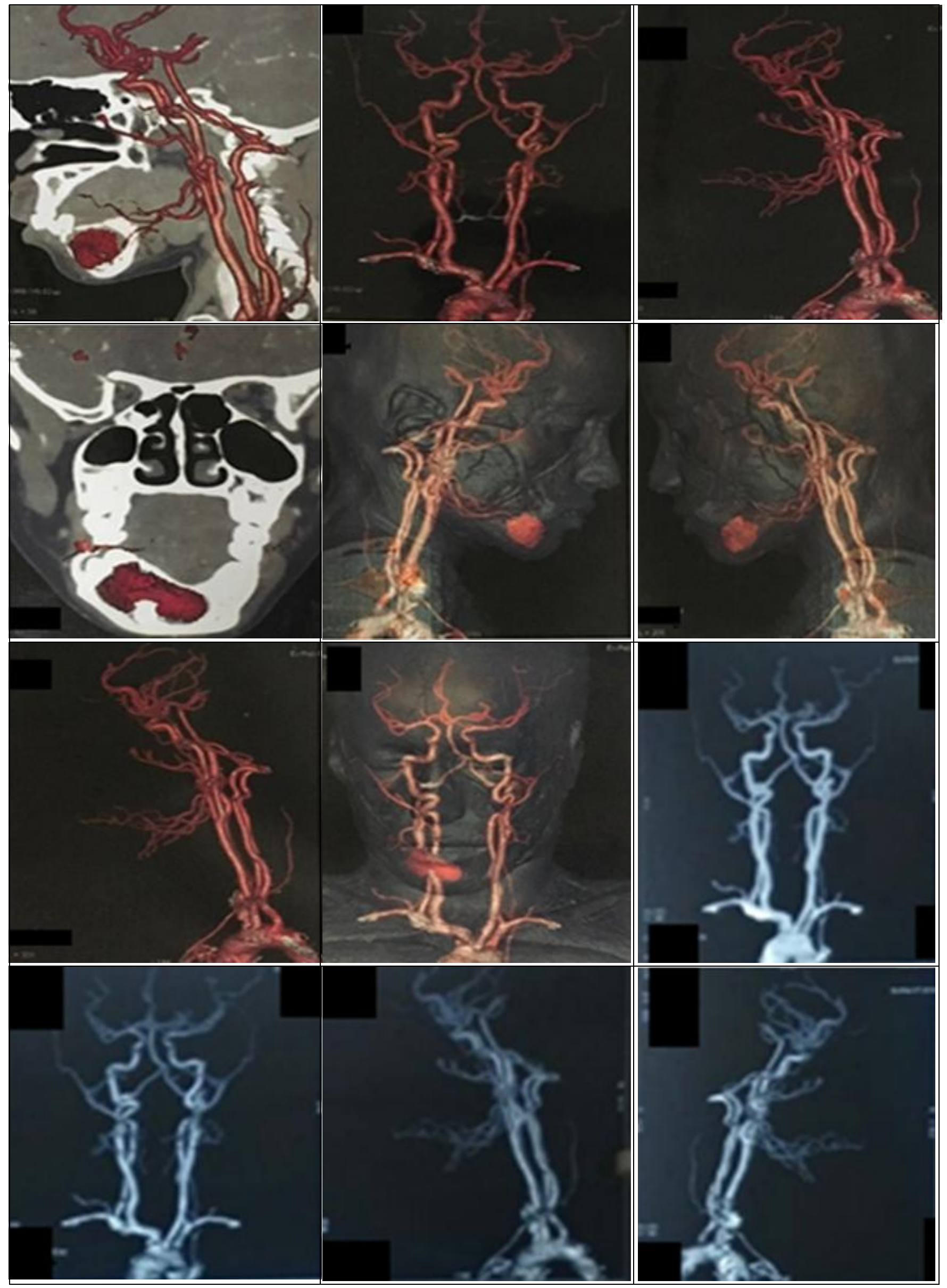



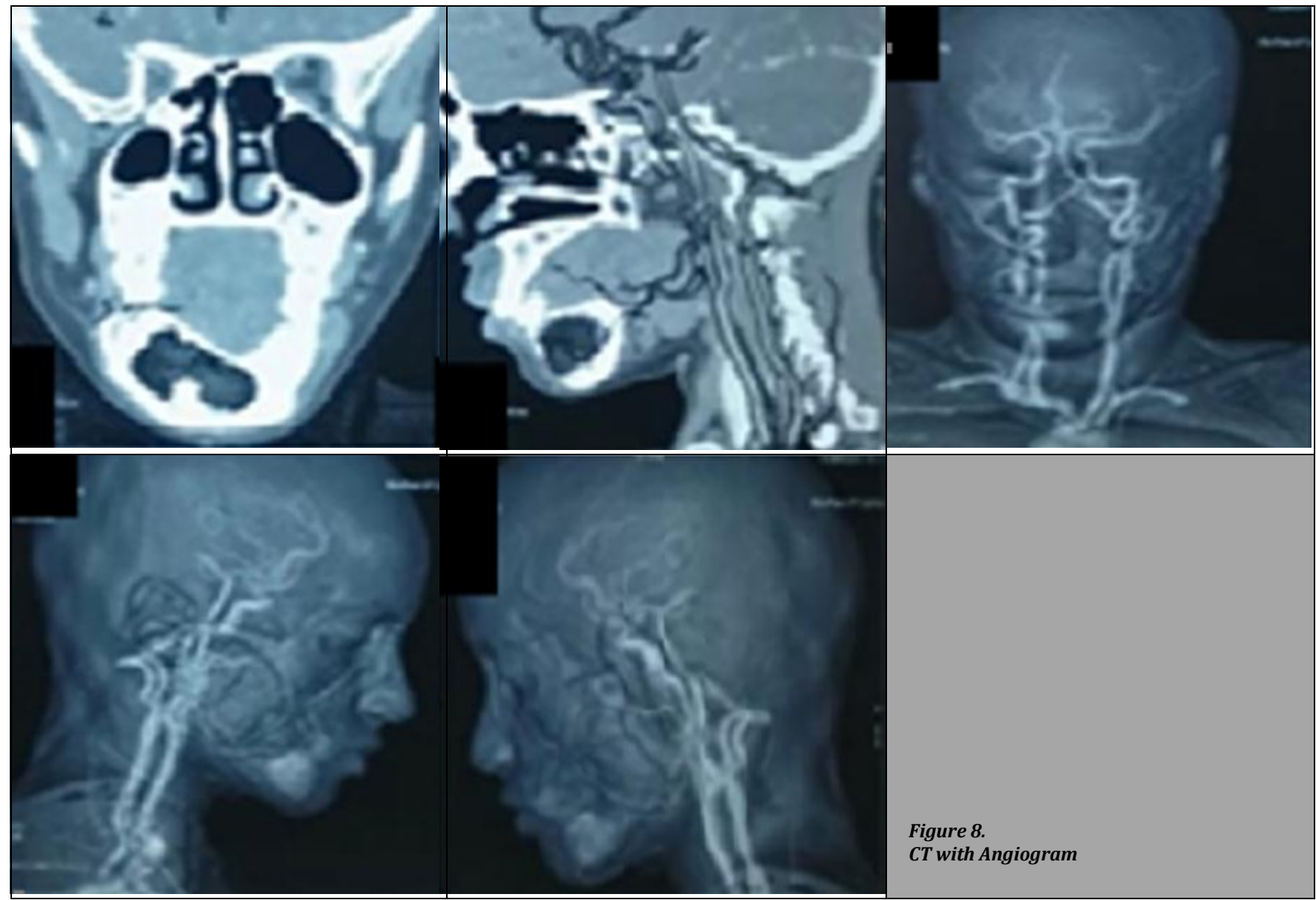

Aspiration of fluid from the lesion was blood tinged. OPG revealed well defined unilocular radiolucency extending from the mesial aspect of 44 to mesial aspect of 46 . Also reveals the presence of impacted premolars and ectopically positioned canine. Only $1.5 \mathrm{~mm}$ of lower inferior border was present (Figure 4, 7).
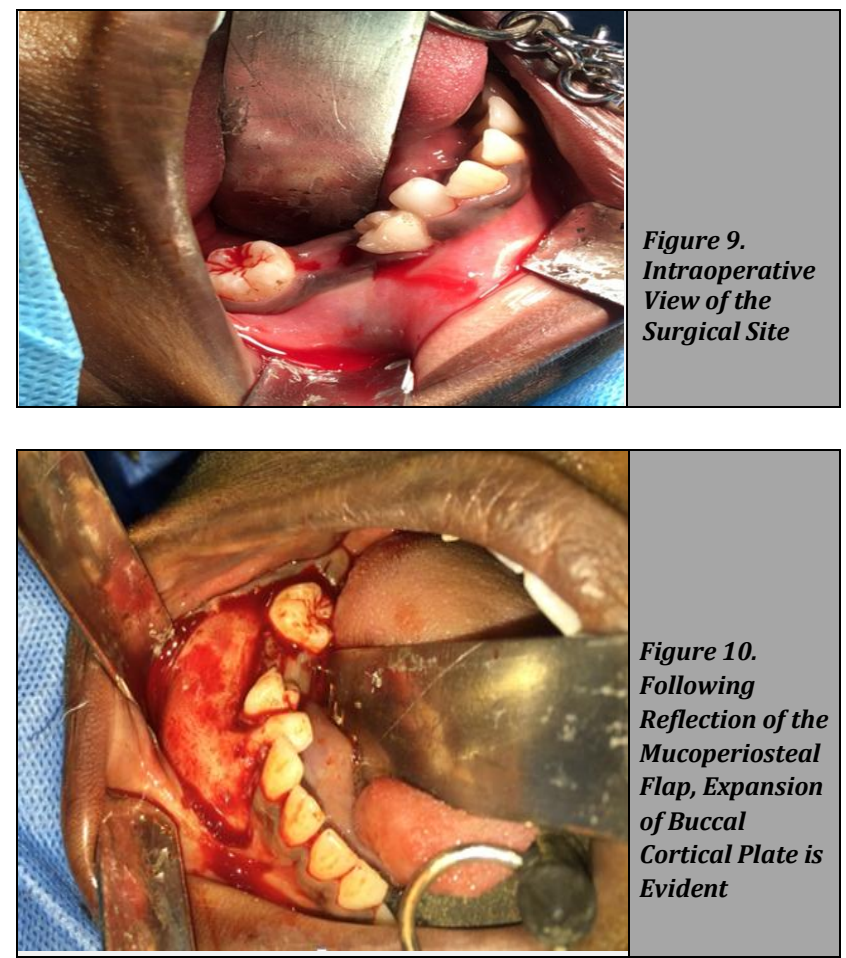

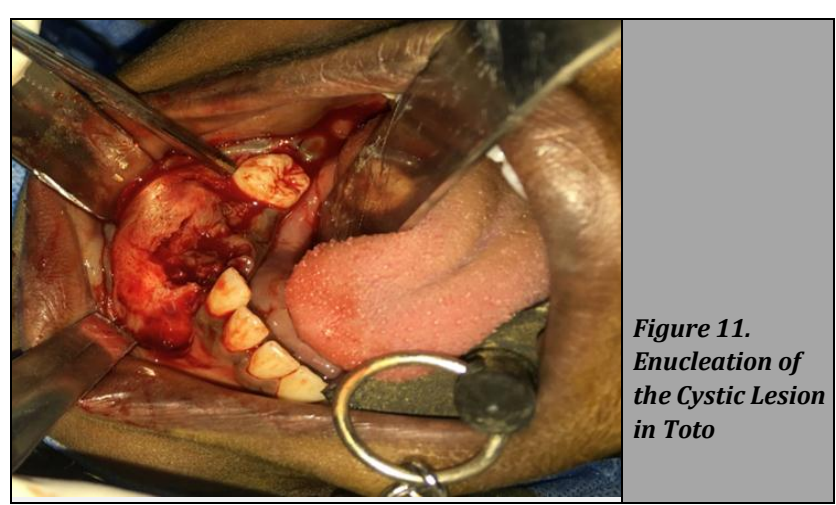

A CT (Computed Tomography) facial bone-mandible with angiogram was also taken which revealed a well-defined unilocular expansile cystic lesion with smooth, corticated margins extending over mandibular symphysis and adjacent anterior body of mandible on the right side (Figure 5). The lesion measured 2.9 (cranio-caudal) x 1.9 (AP) x 3.3 (width) $\mathrm{cm}$. Unerupted teeth was seen within the lesion (Figure 6). No demonstrable feeding artery or obvious feeding draining vein from the lesion noted (Figure 8).

A provisional diagnosis of the periapical cyst, odontogenic keratocyst, dentigerous cyst, and unicystic ameloblastoma was arrived at.

Excisional biopsy of the cystic lesion was carried out under GA (General Anaesthesia). Figure 9 shows the obliteration of lower right buccal vestibule. Following incision and raising a mucoperiosteal flap, wide buccal cortical bone expansion (Figure 10) can be noted which was the cause for obliteration of lower right buccal vestibule. Enucleation of the lesion was done in toto along with the impacted permanent tooth buds of 
canine and premolars (Figure 11, 12). Following excision, peripheral ostectomy was done using a vulcanite bur and antibiotic gauze pack and primary closure was done (Figure 13).
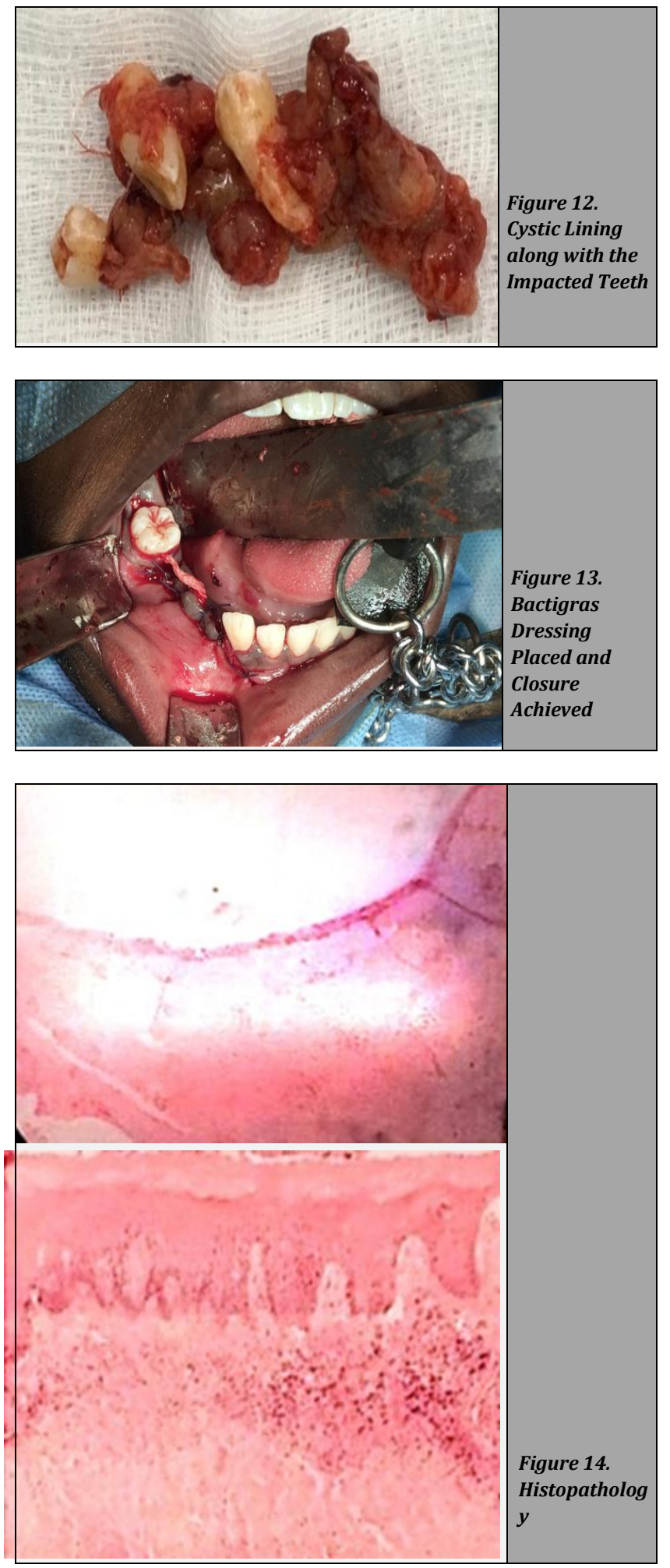

Histopath examination of the biopsy specimen revealed thin odontogenic epithelium of $3-4$ layers thickness with few areas showing evidence of rete ridges and excessive keratinization (Figure 14). The subjacent connective tissue stroma showed intense chronic inflammatory cell infiltrate predominantly lymphocytes. There were also few areas of calcification and luminization of blood vessels. Haemorrhage and peripheral resorbing bone was also present. And the diagnosis was given as "infected dentigerous cyst with keratinization". The patient was followed up and no recurrence was noted (Figure 15 - 18).
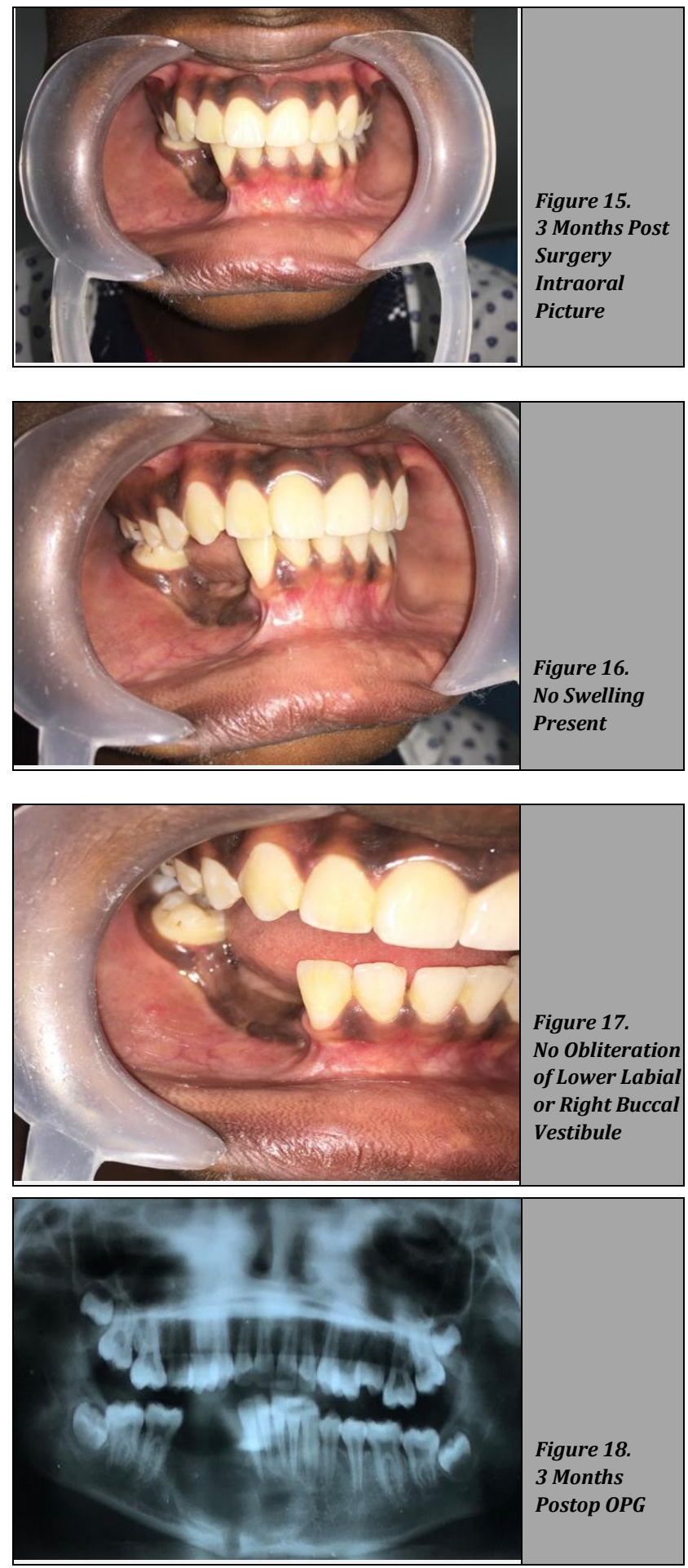

\section{DISCUSSION}

Teeth that are present in areas other than the alveolar arch have been termed as ectopic. Ectopic eruption of tooth is very rare; however, there are reports of a tooth in the nose, condyle of mandible 8 and coronoid process of mandible ${ }^{9}$ which have been mentioned in the literature. 
Ectopic eruption occurs due to any one of the following three processes. ${ }^{10}$ Abnormal tissue interactions during tooth development between the oral epithelium and the underlying mesenchyme may result in ectopic tooth eruption. Iatrogenic causes where the maxillary third molar gets displaced into the maxillary sinus can occur during traumatic extraction. The pathological process where displacement of the tooth buds occurs due to the expansion of the progressively growing dentigerous cyst may result in displacement and also ectopic eruption of the tooth in the other areas.

In this present case, the aetiology was a dentigerous cyst, and the impacted tooth was close to the lower border of mandible.

The association of a supernumerary tooth with a dentigerous cyst is rare condition, and this constitutes about 5 $\%-6 \%$ of all dentigerous cysts. ${ }^{4}$ Although dentigerous cysts have been reported in children, they usually occur in the second or third decades of life and are very rare in early childhood. ${ }^{11}$ Males are predominantly affected $(1.84: 1) .{ }^{5}$ Dentigerous cysts can be multiple and bilateral in patients such as nevoid basal cell syndrome and cleido-cranial dysplasia or may be seen in nonsyndromic patients as well. ${ }^{11}$

Radiographic examination of a dentigerous cyst is a unilocular radiolucency with sclerotic border of varying sizes attached to the cemento-enamel junction of the crown of an unerupted tooth. If the cystic space is greater than $5 \mathrm{~mm}$ in the radiograph, then an odontogenic cyst may be suspected.

An Orthopantomogram (OPG) is a simple, inexpensive radiographic method for viewing an ectopic tooth. However, a CBCT (Cone Beam Computed Tomography) may have an edge over conventional radiography as it provides superior detail of the bony cortical and cancellous plates and helps to appreciate and identify the size and extent of the lesion.

In the present case, CT was helpful in locating the supernumerary tooth which was lying close to the lower border and also in determining the extent of the cyst which was not appreciated on the OPG.

Histopathologically, dentigerous cysts consists of a single layer of nonkeratinized stratified squamous epithelium, surrounded by thin connective tissue wall. In the present case, the lining was of variable thickness, and the connective tissue showed chronic inflammatory cell infiltrate. The cyst was quite large enough to be in close proximity to the roots of the mandibular central incisors. The aspirated fluid also contained red blood cells.

Cases of ameloblastoma, epidermoid carcinomas, and intraosseous squamous cell carcinoma which develops from the epithelium lining the dentigerous cyst have been documented. ${ }^{12,13}$

The standard surgical management for a dentigerous cyst is enucleation along with the extraction of the associated tooth. In case of large cysts, initial marsupialization is done to reduce the size of bony defect followed by enucleation and extraction of the tooth. However, the recurrence or incomplete removal of the lesion resulting in persistence of the lesion is a major disadvantage. In the present case, there was no evidence of any recurrence.

\section{CONCLUSIONS}

Ectopic supernumerary teeth associated with a dentigerous cyst are a rare phenomenon. Advanced imaging techniques may be useful in treatment planning.

Financial or other competing interests: None.

Disclosure forms provided by the authors are available with the full text of this article at jemds.com.

\section{REFERENCES}

[1] Tournas AS, Tewfik MA, Chauvin PJ, et al. Multiple unilateral maxillary dentigerous cysts in a non syndromic patient: a case report and review of the literature. Int J Pediatr Otorhinolaryngology Extra 2006;1(2):100-6.

[2] Browne RM, Smith AJ. Pathogenesis of odontogenic cysts. In: Browne RM, edr. Investigative pathology of the odontogenic cyst. Boca Raton: CRC Press 1991: p. 88-109.

[3] Di Pasquale P, Shermetaro C. Endoscopic removal of a dentigerous cyst producing unilateral maxillary sinus opacification on computed tomography. Ear Nose Throat J 2006;85(11):747-8.

[4] Lustmann J, Bodner L. Dentigerous cysts associated with supernumerary teeth. Int J Oral Maxillofac Surg 1988;17(2):100-2.

[5] Jones AV, Craig GT, Franklin CD. Range and demographics of odontogenic cysts diagnosed in a UK population over a 30-year period. J Oral Pathol Med 2006;35(8):500-7.

[6] Grover SB, Singh P, Venkatachalam VP, et al. Mesiodens presenting as a dentigerous cyst: case report. Indian J Radiol Imaging 2005;15(1):69-72.

[7] Lin IH, Hwang CF, Su CY, et al. Intranasal tooth: report of three cases. Chang Gung Med J 2004;27(5):385-9.

[8] Yusuf H, Quayle AA. Intracondylar tooth. Int J Oral Maxillofac Surg 1989;18(6):323.

[9] Fernandez TM, Meraz TMA. Infected cyst in the coronoid process. Oral Surg Oral Med Oral Pathol 1992;73(6):768.

[10] Bodner L, Tovi F, Bar-Ziv J. Teeth in the maxillary sinus imaging and management. J Laryngol Otol 1997;111(9):820-4.

[11] Ustuner E, Fitoz S, Atasoy C, et al. Bilateral maxillary dentigerous cysts: a case report. Oral Surg Oral Med Oral Pathol Oral Radiol Endod 2003;95(5):632-5.

[12] Rajendran R. Cyst and tumors of odontogenic origin. In: Rajendran R, Sivapathasundharam B, eds. Shafer's Textbook of Oral Pathology. $5^{\text {th }}$ edn. New Delhi: Elsevier Publishers 2006: p. 360-1.

[13] Yasuoka T, Yonemoto K, Kato Y, et al. Squamous cell carcinoma arising in a dentigerouscyst. J Oral Maxillofac Surg 2000;58(8):900-5. 